\title{
VIETNAM'S HEALTHCARE SYSTEM DECENTRALIZATION: HOW WELL DOES IT RESPOND TO GLOBAL HEALTH CRISES SUCH AS COVID-19 PANDEMIC?
}

Huy Van Nguyen 1,2,3, Joseph Debattista4, Minh Duc Pham5, 6, An Thi Minh Dao3, Stuart Gilmourl, Hoa Lan Nguyen2, Tien Van Nguyen7,8, Phuong Mai Le', Phuong The Nguyen', Anh Thi Ngoc Tran', Kien Duy Vu10, Son Thai Dinh'3, Minh Van Hoang 11,12

1. Graduate School of Public Health, St. Luke's International University, Tokyo, Japan

2. Department of Population and Quantitative Health Sciences, University of Massachusetts Medical School, MA, USA

3. Institute for Preventive Medicine and Public Health, Hanoi Medical University, Hanoi, Vietnam

4. Metro North Public Health Unit, Metro North Hospital and Health Service, Queensland Health, Brisane, Australia.

5. Burnet Institute, Melbourne, Australia

6. Department of Epidemiology and Preventive Medicine, Monash University, Melbourne, Australia

7. Faculty of Public Health, Thai Binh University of Medicine and Pharmacy, Thai Binh, Vietnam,

8. Department of Preventive Medicine, Tokushima University Graduate School of Biomedical Sciences, Japan

9. Graduate School of Cancer Science and Policy, National Cancer Center, Korea

10. OnCare Medical Technology Company Limited, Hanoi, Vietnam

11. Hanoi University of Public Health, Ha Noi, Vietnam

12. National Institute of Health Sciences, Bach Mai Hospital, Ha Noi, Vietnam

Correspondence: tiennv@tbump.edu.vn

\begin{abstract}
This article discussed Vietnam's ongoing efforts to decentralize the health system and its fitness to respond to global health crises as presented through the Covid-19 pandemic. We used a general review and expert's perspective to explore the topic. We found that the healthcare system in Vietnam continued to decentralize from a pyramid to a wheel model. This system shifts away from a stratified technical hierarchy of higher- and lower-level health units (pyramid model) to a system in which quality healthcare is equally expected among all health units (wheel model). This decentralization has delivered more quality healthcare facilities, greater freedom for patients to choose services at any level, a more competitive environment among hospitals to improve quality, and reductions in excess capacity burden at higher levels. It has also enabled the transformation from a patient-based traditional healthcare model into a patient-centered care system. However, this decentralization takes time and requires long-term political, financial commitment, and a working partnership among key stakeholders. This perspective provides Vietnam's experience of the decentralization of the healthcare system that may be consider as a useful example for other countries to strategically think of and to shape their future system within their own socio-political context.
\end{abstract}

\section{KEYWORDS}

Healthcare system; Global health crises; Covid-19 pandemic; Low- and middle-income countries (LMICs); Public health responses; Vietnam 
Effective healthcare is provided in the context of appropriate health policy and a well-functioning health system. The Vietnamese health system comprises the two main components of curative and preventive medicine. Over previous decades, the country has succeeded in improving many health indicators relative to its socioeconomic status. However, to be more effective, the health system needs to be adaptive to new contexts. Since

2015 the Vietnamese health system has begun decentralizing from a pyramid to a wheel (Hub and Spoke) model of service organization and delivery. [1, 2] This process of change has raised a number of questions regarding the system's fitness to the globalized context, complex disease pattern and ability to respond to global health crises such as the current Covid-19 pandemic. The objective of this commentary is to provide insights into these issues to better understand a unique health system in its decentralization. We focus our discussion on the public curative system (also known as the public healthcare system) rather than on the preventive medicine component of Vietnam's healthcare system.

\section{CONCEPT OF PYRAMID AND WHEEL MODELS}

The pyramid model of organization is best defined as a triangle structure, starting with a single point at the top - the highest level, gradually spreading out towards the base the lowest level. [3] A pyramid model is used to refer to a hierarchical system of ascending levels (from the base) of organization where each level medically and technically complements the preceding level, and the capacity of the lower level is less than the upper (Figure 1). In this model, interventions implemented at lower levels are designed to target broader segments of society with less intensity of resources and medical technology, which may improve their effectiveness in the context of limited resources available to low- and middle-income countries. [4]

On the other hand, the wheel model is represented by a circular "Hub and Spoke" framework, starting from a central hub and spreading out along "spokes" towards surrounding nodes (Figure 2). Under this model, the surrounding nodes provide high health care services for residents living in catchment areas as well as those from the other regions at the user's choice. The central hubs serve the general population nationwide with highly advanced technology and facilities. Both the central hub and surrounding nodes are linked so as to mutually support the overload of patients and the central hubs providing technology transfer to the surrounding nodal services. Thus, there is little technical demarcation in the circle model as compared with the pyramid model. The effectiveness of public health interventions in a wheel model has been demonstrated in nursing practice, health education, and administration. [5]

\section{DECENTRALIZATION FROM PYRAMID MODEL TO WHEEL MODEL IN VIETNAM}

Figure 1 shows the current public healthcare system organization model in Vietnam. According to this model, the healthcare system follows a pyramid framework and organized with four administrative levels at central, provincial, district, and commune levels. The central-level hospitals, located at the apex of the framework, typically provide specialist services, technical support and training for the lower levels. [6] Provincial and district health facilities provide general, less technical services. At the lowest commune level, community health stations (CHSs) deliver primary health care. Although this organizational structure has been gradually improved over the past decade, it still has several limitations. As Vietnam enters an epidemiological transition with increasing complexities of disease - i.e. a triple-burden pattern of slowly declining communicable diseases (CD), rapidly increasing noncommunicable diseases (NCD), and intermittently remerging diseases, the gaps in healthcare services across different levels are becoming wider. [7] Since the lower health service levels (district and commune) are not allowed and sometimes not able to perform complex medical care or better treat common health conditions, patients tend to bypass $\mathrm{CHSs}$ or district health units to seek services at higher service levels (provincial or central), creating a significant patient overload at the provincial or central levels and under-utilization of services at lower levels. $[8,9]$

Recently, in an effort to address the above challenges, Vietnam has started to shift from a pyramid model to a wheel (Hub and Spoke) model (figure 2). First, at an annual health review conference hosted by the Vietnamese Ministry of Health (VMOH) in 2014, directors and managers of the district and provincial hospitals requested that their hospitals be re-designated as regional rather than district and/or provincial hospitals and to receive more investment from the government and the $\mathrm{VMOH}$ to improve their facilities comparable to the central level.

Second, hospitals have undergone a process of being 
reclassified as per hospital ranking standards by $\mathrm{VMOH}$. Hospitals are now ranked at four quality levels, with grade 1 represents the highest standard, inclusive of 39 central hospitals, 69 provincial hospitals and 1 district hospital. [6] At the district level, lower grade 3 and 4 hospitals are required to merge as Centres for Disease Control and Prevention (CDC) to provide both prevention and treatment, whilst higher-grade hospitals (1 or 2) are allowed to be separate from CDC. [7] Higher-grade hospitals receive more finance for healthcare from the government and are allowed to perform high tech services. This new reclassification placed lower-grade district hospitals (grade 3 or 4) under increased pressure to improve and upgrade services to a higher grade. It also improved the integration of health facilities for treatment, disease control and prevention as lower-grade hospitals become as part of CDC.

Third, there are several policy documents with specific regulations which have allowed cross-district linkage of health insurance payments at the district level since 2016 , and future linkage at the provincial level from 2021. [10] These policy initiatives enable more freedom for patients to choose their own services at the district or provincial levels, rather than restricted referral to the district or provincial service within the patient's residential areas. Under this new linkage policy, most patients choose high quality hospitals. These policies of patient choice have also created a competitive environment among hospitals leading to quality improvement, so patients have more options to utilize high quality services right at district hospitals.

\section{SUITABILITY OF THE REFORMED SYSTEM FOR GLOBAL HEALTH CHALLENGES}

Any health system organization (and its transformation) should reflect the socio-economic development of a country and address the needs of its population as they change with changing epidemiology. In Vietnam, this health system decentralization helps address three objectives:

(1) to strengthen system capacity for quality of care improvement, particularly at primary level,

(2) to improve patient/user satisfaction, providing more freedom to choose providers and services

(3) to improve system efficiency with limited resources to better respond to more complex disease patterns (e.g., the double burden of communicable and noncommunicable diseases) and public health emergencies (e.g., SARS, Covid-19 or other pandemics).
In this decentralization, the establishment of "regional hospitals" with the Government's investment in both facilities and human resources is expected to improve the system capacity to provide high-tech, high-quality services at the district and provincial level. Such services have previously been only available at the central level. This approach has provided patients more options to receive services at a facility near their residence, avoiding overwhelming demand placed upon central hospitals. In the current setting, this approach has created a wider network of more localized hospitals capable of treating patients with Covid-19. Vietnam's success of containing the Covid-19 pandemic has been internationally wellrecognized with 1343 confirmed cases and 35 deaths by November 30, 2020. [11] Although this achievement has been the result of a range of public health responses, Vietnam's success stems from its ability to strategically implement those responses and enabled by its process of health system transition and adaptation. The intensive training and capacity building introduced for lower-level hospitals as part of this decentralization process, established more localized facilities for the management of Covid-19 patients. Similarly, the establishment of CDCs, not only generated more integrated and multi-function facilities, but also improved the system to address local needs while maintaining strong and timely responses to future public health emergencies as observed in the current Covid-19 pandemic.

\section{CHALLENGES AHEAD}

While it has been appreciated for ongoing efforts and positive signs of decentralisation, Vietnam has been facing several challenges. Despite the fast economic growth since the early 1980s known as Doi Moi policy, it hasn't lasted for long perhaps due to a lack of strategic and sustainable socio-economic development plans. [12, 13] This unstable growth not only affects the resource allocation for different sectors and industries, but also does so for process of health system decentralization. The process of economic transition and healthcare system decentralization, while bringing more benefits to both economy and health sector, has also created more elites and access to and use of high-quality health services among the high social class due to widened social inequality. $[12,14]$ This means that the country also needs to address other emerging issues as a result of this process. Noticeably, the most critical error for decentralization is to define it as a managerial exercise rather than a political mechanism. [15] 


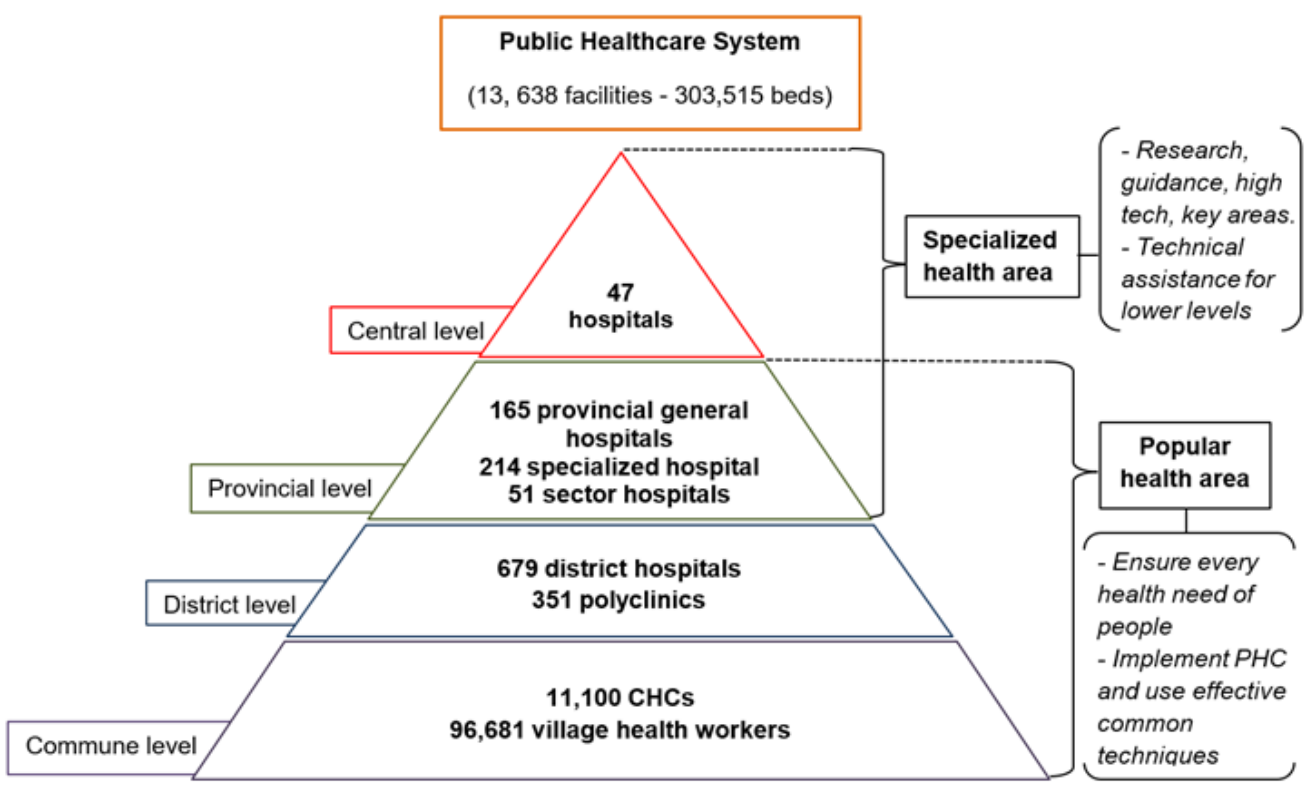

FIGURE 2. THE TRANSITION FROM THE PYRAMID MODEL TO WHEEL MODEL IN THE PUBLIC HEALTHCARE SYSTEM IN VIETNAM

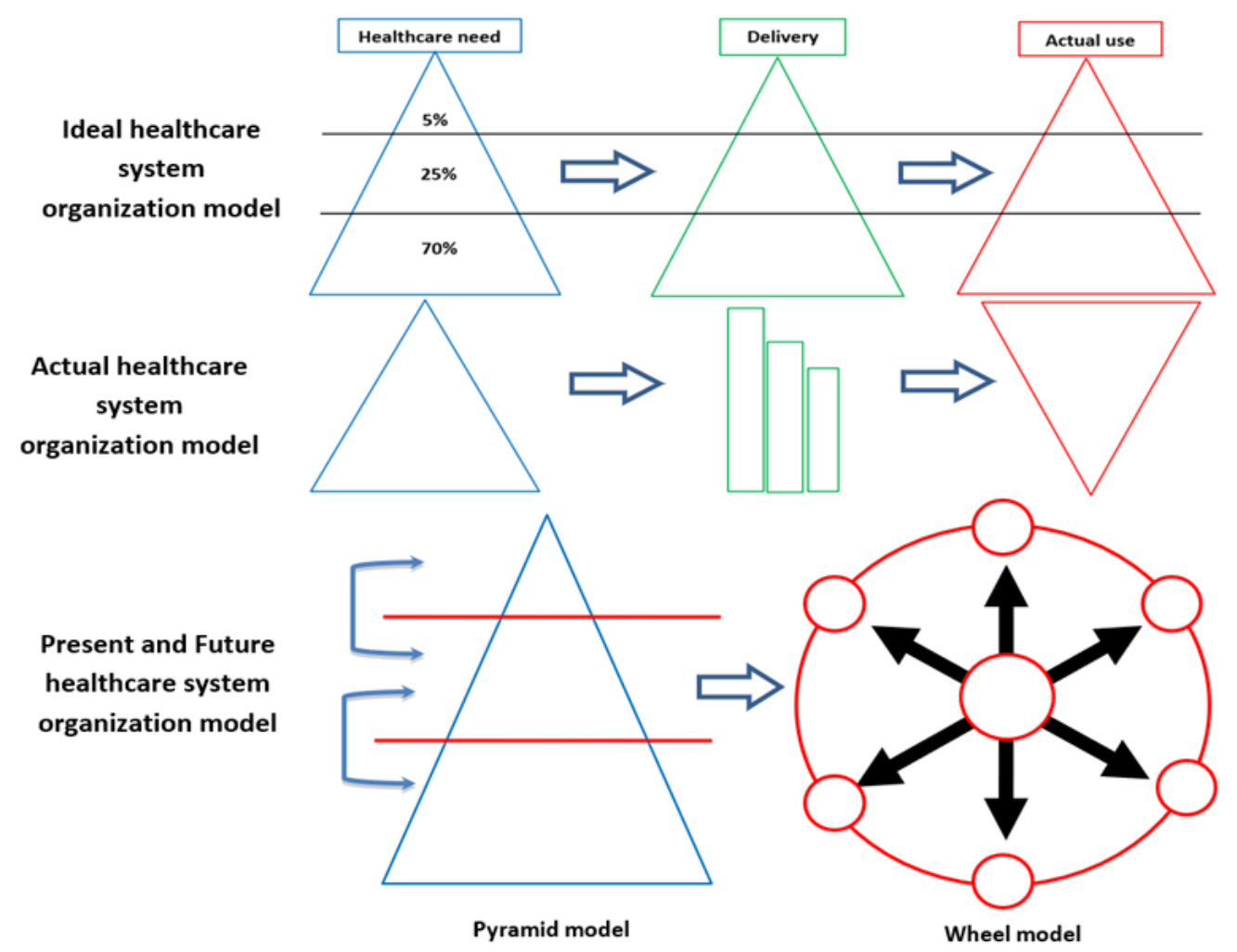

Notes: The ideal pyramid model (at the top) represents a perfect matching between healthcare need, delivery and actual use where most clients (70\%) use the lower-grade services (commune and district hospital services) and few (about 5\%) seek the topic-grade services. However, the model of actual healthcare use is reversed in the middle pictures. 
The pyramid model has clearly shown its limitations in Vietnam, with significant gaps emerging across different healthcare system levels leading to an overwhelming of capacity of centralized hospitals and underutilization of hospitals at district/provincial levels. The system organization and service delivery models were in need of decentralization, and this process has been initiated in Vietnam for a long time and now is still ongoing. The available evidence suggests that the country is on the right track. However, this decentralization will be challenged, take time and require long-term political and financial commitment, and effective collaborative processes among local authorities, the $\mathrm{VMOH}$, hospitals and public health agencies at various levels. The success of this decentralization, therefore, remains to be seen but the future will inevitably belong to a patient-centred healthcare system with the ultimate goal of health care for all. The decentralization of the healthcare system in Vietnam may provide much insight for other low- and middle-income countries reshaping their system to handle the new complexities of the epidemiological transition and new emerging global health crises. Both opportunities and challenges are ahead. The time to reflect, imagine and act is now.

\section{References}

1. Ministry of Health and Ministry of Internal Affairs of Vietnam. Joint Circular No. 51/2015/TTLT-BYT-BNV dated December 11, 2015 guidelines for Functions, Tasks, Entitlements and Organizational Structure of Departments of Health Affiliated to People's Committees of Provinces and Central-Affiliated Cities 2015 [Available from:

http://vbpl.vn/bonoivu/Pages/vbpq-van-bangoc. $\operatorname{aspx}$ ? $\mid$ temlD=94029

2. Ministry of Health of Vietnam. Vietnam Hospital Quality Standards (version 2.0). Vietnam: Issued in accordance with Decision No. 6858/QD-BYT dated 18/11/2016 of the Health Minister, Vietnam; 2016.

3. Long N.H. Vietnam Health System. Lecture. Hanoi Medical University. 2015.

4. Frieden TR. A framework for public health action: the health impact pyramid. American journal of public health. 2010;100(4):590-595.
5. Keller LO, Strohschein S, Lia-Hoagberg B, Schaffer MA Population-based public health interventions: practice-based and evidence-supported. Part I. Public health nursing (Boston, Mass). 2004;21 (5):453468.

6. Ministry of Health of Vietnam. Health Statistics yearbook 2016: Medical Publishing House; 2016.

7. Vuong DA, Van Ginneken E, Morris J, Ha ST, Busse R. Mental health in Vietnam: Burden of disease and availability of services. Asian journal of psychiatry. $2011 ; 4(1): 65-70$.

8. Lee HY, Oh J, Hoang VM, Moon JR, Subramanian SV. Use of high-level health facilities and catastrophic expenditure in Vietnam: can health insurance moderate this relationship? BMC health services research. 2019;19(1):318.

9. The World Bank. Moving toward UHC : Vietnam national initiatives, key challenges, and the role of collaborative activities2017. 1-9 p.

10. The National Assembly of Vietnam. Law No. $46 / 2014 / \mathrm{QH} 13$ on amendments to some articles of the Law on Health Insurance [Internet] 2014 [Available from:

http://vanban.chinhphu.vn/portal/page/portal/chinh phu/hethongranban? class id $=1$ \& page $=1$ \& mode $=d$ etail\&document id $=175349$

11. Ministry of Health of Vietnam. COVID-19 Information [Internet] 2020 [Available from:

https://ncov.moh.gov.vn/

12. Vuong QH. Vietnam's political economy in transition 2017 [Available from: https://www.stratfor.com/thehub/vietnams-political-economy-transition-1986-2016. Accessed January 8, 2017

13. Målqvist M, Dinh TPH, Thomsen S. Causes and determinants of inequity in maternal and child health in Vietnam [published online ahead of print August 11, 2012]. BMC Public Health. 2012;12:641.

14. Målqvist $M$, Lincetto $O$, Nguyen $H$, Burgess $C$, Dinh $T$. Maternal health care utilization in Viet Nam: increasing ethnic inequity. Bull WHO. 2013;91:254-261.

15. Omar M. Health sector decentralization in developing countries: unique or universal. World Hosp Health Serv. 2002;38(2):24-30. 